\title{
Pregnant Supports on Hemodynamics Responses during Postural Changes and Daily Physical Activities: a randomized control trial
}

\section{Kunanya Masodsai}

Faculty of Sports Science, Chulalongkorn University

\section{Sasipa Buranapuntulug}

Faculty of Allied Health Sciences, Thammasat University

Parunchaya Jamkrajang

College of Sports Science and Technology, Mahidol University

\section{Pei-Ni Chen}

College of Sports Science and Technology, Mahidol University

Rungchai Chaunchaiyakul ( $\nabla$ gmrungchai@gmail.com )

College of Sports Science and Technology, Mahidol University

\section{Research Article}

Keywords: maternal wear, blood perfusion, pregnant, last trimester

Posted Date: February 26th, 2021

DOI: https://doi.org/10.21203/rs.3.rs-207286/v1

License: (9) This work is licensed under a Creative Commons Attribution 4.0 International License. Read Full License 


\section{Abstract}

\section{Background}

Pregnant supports have been designed to prevent structural deviations but may impair blood circulation of the lower limbs, in particular during the last trimester. In this study, we evaluate the effect of different pregnant supports on hemodynamics responses during postural changes and daily physical activities.

\section{Methods}

Twelve last-trimester healthy pregnant women participated in this study. With randomized supports of casual wear (CW), pelvic band (PB), and pregnant pants (PP), subjects performed postural changes (standing and side lying using sitting as control), daily physical activities (climbing up and down stairs, lifting, sit-to-stand, and 10 min walking), and routine pregnant exercises. Hemodynamic responses including heart rate, blood pressure, stroke volume, cardiac output, local blood flow, and perfusion around the ankle were measured at the end of the $1 \mathrm{st}$ and $3 \mathrm{rd}$ minute after wearing pregnant supports.

\section{Results}

Standing position in CW group showed hemodynamic compensations via increasing diastolic blood pressure (DBP, 1st minute) and heart rate (HR, 3rd minute), whereas there were no significant changes in the PB and PP groups. Side lying position lowered cardiac responses in all groups, with higher blood perfusion in CW and PB, but not in PP. Cardiac variables, blood flows, and perfusions showed no significant difference among pregnant supports during daily physical activities, and routine pregnant exercises. The satisfaction evaluation on daily activities and routine exercises showed no difference among pregnant supports but the preferential pregnant support is PB.

\section{Conclusion}

It can be concluded that PB offers similar hemodynamic adjustments during postural changes as casual wear. PB support is recommended for pregnant women for daily physical activities, as well as routine exercises.

Trial registration: The trial is retrospectively registered in http://www.clinicaltrials.in.th (01/02/2021) with trial no: TCTR20210201003.

\section{Background}

During pregnancy, a woman's body undergoes both physical and physiological challenges due to the progressively growing fetus [1], and hormonal-induced loosening up of ligaments [2]. The above factors will cause structural deviations, particularly during the last two trimesters [3]. Consequently, these changes bring about physical limitations and sedentary behavior among pregnant women, which have been associated with increased risks of abdominal glucose tolerance, gestational diabetes, and 
preeclampsia [4-6]. In some cultures pregnant women are not allowed to work and are even asked to avoid some postures [7]. In pregnant women, blood pressure deviations and heart tolerance may appear during postural changes and physical activities [8]. Pregnant supports are aimed to relieve these problems.

Wearing tight dresses clearly limit some posture and physical abilities and can lead to discomfort [9]. Previous studies reported that tight clothing may be related to constipation [10], worsening of autonomic nervous system [11] and digestive functions [12], decrease in trunk muscle strength, and increased risk of lumbar problems [13]. During the 4th month of pregnancy, the growing fetus causes reduction in venous return of the supine position due to compression of the vena cava and big arteries in the pelvic floor. This results in fluctuations in cardiac output and blood pressure during daily life [14]. Pregnant supports have been designed to reduce pain, discomfort and better perception on body contour [15]. Despite many maternal products, the alterations on hemodynamics from pregnant supports have rarely been investigated. In this study, we evaluate the two common pregnant supports on hemodynamic adjustments of the lower limbs during postural changes and physical activities in pregnant women during the last trimester.

\section{Methods}

\section{Participants}

Twelve pregnant women (20-30 years of age), calculated from previous similar study, from the Maternal Clinic of Thammasat University Hospital voluntarily participated in this study. Inclusion criteria are those within the last trimester of pregnancy, having good health, no history of cardiorespiratory or musculoskelatal problems, anemia, hypertension, preclampsia, and diabetes mellitus. After screening by an obstetrician, the experimental procedures were clarified along with the possible risks and benefits of the study.

Written informed consent forms were signed.

All tests were conducted within the same room with $25^{\circ} \mathrm{C}$ at College of Sports Science, Mahidol University. The instructions were explained to the subjects a few days prior to the test. These included work/rest periods, regular meals and ad libitum of water, avoidance of chocolate, coffee, tea, and alcohol beverages, etc.

This study was approved by the Institution Research Board of Mahidol University (MU-IRB 2012/129.2607) with Thai Clinical Trials Registry number of TCTR20210201003.

\section{Experimental protocol}

The height, body mass index (BMI), total body weight, fat percentage, free fat mass, visceral fat, muscle mass, bone mass, and basal metabolic rate (BMR) of participants were evaluated (Bioelectric impedance analyser, Tanita SC330, Japan). Subjects had to complete three parallel randomized interventions of casual wear (CW, daily home-based loose wear served as control condition), pregnant pelvic band (PB), 
and pregnant pant (PP) (Fig. 1). The randomized sequence of all intervention was completed by an only female investigator. Hemodynamic functions, including heart rate (HR), stroke volume (SV), cardiac output (CO), ejection fraction (EF), and systemic vascular resistance (SVR) were identified using noninvasive method of impedance cardiographs (Physioflow, Manatec Biomedical, France). Systolic and diastolic blood pressures (SBP and DBP respectively) were measured using the sphygmomanometer. Blood flow and perfusion were estimated at the dorsalis pedis artery and the adjacent skin area using an ultrasound Doppler (Vascular Assist, Huntleigh, UK) and laser Doppler (MoorVMS-LDF, UK) respectively. These hemodynamic variables were collected for the first $15 \mathrm{sec}$ of the $1 \mathrm{st}$ and 3rd minutes [16] after subjects changed to a new support, during postural changes, daily physical activities, and routine pregnant exercises [17].

Subjective evaluation was done using a modified questionnaire $[18,19]$. It contained personal information, and satisfaction indices from postural changes and physical activities. With a five-point scale, this questionnaire was used to estimate the satisfaction indices while the subject performed 2 activities of daily physical activity, and routine pregnancy exercises.

\section{Statistical analysis}

All data were presented as means and standard error of mean (SEM). The SPSS statistical package (version 21; SPSS, BMI, New York, USA) was used to analyze the data. The difference between the data collected was determined using Repeated-measured ANOVA with Tukey post-hoc test. Statistical significance was accepted when $p<0.05$.

\section{Results}

Five subjects were eliminated due to scoliosis, acute severe back pain, and legs edema. The remaining twelve participants had normal condition with no impact of acute malnutrition and gestational diabetes mellitus during the period of this study. Anthropometric data (means and standard deviations) including age, body weight, and height were $32.8 \pm 5.2$ years, $64.8 \pm 8.0 \mathrm{~kg}$, and $158.4 \pm 6.4 \mathrm{~cm}$ respectively with gestation of $7.6 \pm 0.5$ months. BMl, total body water, body fat, and bone mass percentages, and daily basal metabolic rate were $25.9 \pm 3.2 \mathrm{~kg} / \mathrm{m}^{2}, 47.9 \pm 2.7 \%, 35.1 \pm 4.9 \%, 3.9 \pm 0.3 \%$, and $1284.9 \pm 110.2$ Kcal respectively.

\section{Hemodynamics and Postural Changes:}

Hemodynamic from CW at rest in the sitting position were used as the control (Table 1). The standing position doubled the blood flow to the feet in PB at min 3 (rest-min $3, p<0.05$ ), with higher DBP (rest-min $1, \mathrm{CW}, \mathrm{p}<0.05)$ and higher HR (rest-min $3, \mathrm{CW}, \mathrm{p}<0.05)$.

Side lying position caused immediate higher blood perfusions in CW (rest-min 1 and rest- $3, p<0.05$ ), and in PB (rest-min 1, $p<0.05$ ). The other hemodynamic in this study showed remarkable reductions during side lying position. There were reductions in SBP in CW (rest-min 3 and min $1-3, p<0.05$ ), in PB (rest-min 
1 and rest-min $3, p<0.05)$, and in PP (rest-min $3, p<0.05)$. DBP showed the reductions in CW (rest-min 1 , rest-min 3, and min 1-min 3, $p<0.05$ ), in PB and PP (rest-min 1, rest-min 3, $p<0.05$ ). There were reductions in HR in CW (rest-min 3, p < 0.05), in PB (rets-min 1, p< 0.05) and in PP (rest-min 1, rest-min 3 , $p<0.05$ ). With the exception of higher CO in PB (rest-min $3, p<0.05), C O, S V, E F$, and SVR showed no significant difference among supports and postural changes. 
Table 1

Comparison of changes in hemodynamics functions with CW, PB, and PP supports during different positions of side lying, and standing (sitting at rest as control).

\section{Standing}

Hemodynamic

CW

PB

PP

Changes

$\begin{array}{lllllll}\begin{array}{l}\text { Rest } \\ \text { (sitting) }\end{array} & \text { Min1 } & \text { Min3 } & \text { Min1 } & \text { Min3 } & \text { Min1 } & \text { Min3 }\end{array}$

Blood flow

$(\mathrm{ml} / \mathrm{min})$

Blood perfusion

(arbitrary unit)

SBP (mmHg)

DBP (mmHg)

HR (bpm)

SV (ml)

$\mathrm{CO}(\mathrm{L} / \mathrm{min})$

$\mathrm{EF}(\%)$

Side Lying

Blood flow

$65.05 \pm$

5.39

$5.97 \pm \quad 6.69 \pm$

0.47

$68.00 \pm \quad 66.81 \pm$

6.06
0.54

$6.80 \pm$

$5.82 \pm$

1.27

$6.55 \pm$

$7.27 \pm$

$1.81^{*}$

$13.69 \pm$

2.55

$15.63 \pm$

3.41

$113.27 \pm$

2.56

$\pm 2.09$

$72.00 \pm$

2.20

$2.08^{*}$

$95.00 \pm \quad 97.92 \pm$

$3.42^{\star}$

$65.45 \pm$

$68.79 \pm$

5.83

$6.71 \pm$

0.65

7.32
$68.85 \pm$

7.61
$12.42 \pm$

2.63

108.40

$\pm 3.20$

$70.60 \pm$

1.82

$95.70 \pm$

3.21

$76.42 \pm$

4.72

$7.77 \pm$

$0.43^{*}$

$75.60 \pm$

6.24
( $\mathrm{ml} / \mathrm{min})$

(arbitrary unit)

SBP (mmHg)

DBP (mmHg)

HR (bpm)

SV (ml)
$3.54 \pm$

0.94

$5.44 \pm$

1.12

$14.55 \pm \quad 22.49 \pm$

2.45

$2.82^{*}$

$5.30 \pm$

1.28

$110.55 \quad 102.80$

$\pm 3.87 \quad \pm 4.66$

$4.07^{\star \#}$

$18.31 \pm$

$2.94^{\#}$

$68.27 \pm \quad 59.60 \pm$

$3.27^{*}$

2.57

$\begin{array}{ll}90.00 \pm & 85.18 \pm \\ 4.09 & 2.97\end{array}$

$65.05 \pm$

5.39
$71.82 \pm$

5.02
$58.64 \pm$

$3.43^{*}$

$83.42 \pm$

$3.84^{*}$

$71.64 \pm$

5.17
$4.90 \pm$

0.85

$76.31 \pm$

5.86
$73.28 \pm$

4.87

$7.38 \pm$

0.50

0.85

$23.07 \pm$

$3.32^{*}$

$98.91 \pm$

$4.11^{*}$

$56.82 \pm$

$2.77^{*}$

$83.91 \pm$

$2.63^{*}$

$76.87 \pm$

5.11

\section{$5.73 \pm$}

1.16

$6.55 \pm$

1.98

$19.26 \pm$

6.39

$18.98 \pm$

7.83

109.36

111.18

$\pm 2.12$

$\pm 3.17$

$71.45 \pm$

2.71

$70.64 \pm$

3.02

$94.82 \pm \quad 92.55 \pm$ $5.34 \quad 5.48$

\section{$68.65 \pm \quad 68.53 \pm$}

5.79

6.24

$\begin{array}{ll}7.06 \pm & 7.07 \pm \\ 0.73 & 0.68\end{array}$




\begin{tabular}{|llllllll|}
\hline Standing & \multicolumn{7}{|c|}{ ( } \\
\hline CO (L/min) & $5.97 \pm$ & $6.07 \pm$ & $6.20 \pm$ & $6.63 \pm$ & $6.55 \pm$ & $5.76 \pm$ & $5.67 \pm$ \\
& 0.47 & 0.41 & 0.50 & 0.42 & 0.44 & 0.65 & 0.65 \\
\hline EF (\%) & $68.00 \pm$ & $67.79 \pm$ & $67.70 \pm$ & $73.28 \pm$ & $69.76 \pm$ & $74.33 \pm$ & $71.03 \pm$ \\
& 6.06 & 5.66 & 4.67 & 4.24 & 4.14 & 4.20 & 4.70 \\
\hline
\end{tabular}

Values reported are means and standard errors at rest during the $1 \mathrm{st}(\min 1)$ and $3 \mathrm{rd}(\min 3)$ after changing to the new position. ${ }^{*} p<0.05$; significant difference from rest; $\# p<0.05$; significant difference from Min 1.

\section{Hemodynamics and Physical Activities:}

Two physical stresses of daily physical activities (Fig. 2) and routine clinical pregnant exercises (Fig. 3) were used in this study. There were no significant changes in hemodynamics during the two physical stresses no matter which pregnant supports were put on. This study determines no limitation of physical activity and routine exercises among pregnant women wearing PB or PP.

Satisfaction evaluation on physical activity in daily life and selected pregnancy exercises obtained from questionnaires were analyzed using $\mathrm{CW}$ data as reference. Immediately after putting on PB and PP these scores were not significantly different among the groups (Table 2). However, the score in PB was the highest for both physical activities in daily life $(p=0.051)$ and pregnancy exercises $(p=0.06)$.

Table 2

Average satisfaction indices of activities in daily life and pregnant exercises.

\begin{tabular}{|llllll|}
\hline & CW & PB & PP & P-value & F \\
\hline Daily activities & $3.63 \pm 0.34$ & $4.61 \pm 0.19$ & $4.40 \pm 0.22$ & 0.051 & 3.78 \\
\hline Pregnant exercises & $3.69 \pm 0.41$ & $4.67 \pm 0.19$ & $4.63 \pm 0.22$ & 0.67 & 3.35 \\
\hline
\end{tabular}

\section{Discussion}

This study demonstrates that pregnant supports assist immediate hemodynamic adjustments during postural changes. It is believed that the elasticity of pregnant supports offer some additional function of baroreceptors in healthy pregnancies in the standing position. As the hydrostatic pressure diminishes during the side lying position, it will lower hemodynamic adjustments with greater immediate blood perfusion With limitation during the last trimester, these compensations cannot be demonstrated in the supine position due to the risk of abdominal aorta compression [20]. Daily physical activity and routine pregnant exercises do not affect hemodynamics. From our results, pregnant supports are recommended with no limitation on lower limb hemodynamics.

The physiologic adjustments in pregnancy to meet the metabolic demands for both mother and fetus are critical, particularly during postural changes and daily physical activities. On the other hand, 
hemodynamic insufficiency during pregnancy leads to complications of pregnant women in North America [21]. Several cardiovascular adjustments in pregnant women necessarily compensate to lower the above risks during pregnancy [22].

The current study aimed to report anthropometric status during the last trimester and will not focus on the dynamic gestational weight gain (GWG). Previous investigations on anthropometry of pregnant women reported wide ranges of BMI from $18-20 \mathrm{~kg} / \mathrm{m}^{2}$ in South Asia [23] and 25.3 up to $68.3 \mathrm{~kg} / \mathrm{m}^{2}$ among the South-Asian pregnant women [24]. With report in South-East Asia, maternal BMI in this study is categorized as the borderline of pregnant obese group [25]. Total body water of $50 \%$ [26] and daily basal metabolic rate of 1300-1400 Kcal are accepted [27]. The dynamic changes in body composition from fluid shifting between mother and the growing fetus may be a major explanation on pregnant anthropometric changes [28]. Other body composition variations during gestation depends on methods being used and will not able to differentiate between mother and fetus [29]. Thus, this study will pay attention on hemodynamics changes.

To our knowledge, this is the first study on hemodynamics in pregnant women during postural changes and physical activities. For safety reasons, invasive methods have rarely been done in pregnant subjects [30], thus, most previous investigations used non-invasive methods of echocardiogram and magnetic resonance images, which are limited by the mother being set in a steady position [31, 32]. To overcome the above limitation, the present study used non-invasive method of impedance cardiographs (Physioflow ${ }^{\circledR}$ ), which shows high validity and reliability and permits continuous measurement in pregnant women during postural changes [33,34].

Pregnancy is associated with various physiologic adaptations to ensure adequate uteroplacental circulation for fetal growth and development [35]. Those hemodynamic compensations involve factors of either inside or outside the heart. Cardiac output increases throughout early pregnancy, and peaks in the last trimester, usually to $30-40 \%$ above baseline. The rise in cardiac output is mediated to estrogeninduced higher overall blood volume, which in turn increases pre-load and stroke volume [22]. A long-term study throughout the period of pregnancy by imaging found that there were fluctuations of SBP and DBP from thickening of intima-media (IM) and inter-adventitial diameter (IAD) of the common carotid artery (CCA) on the first trimester which returned to pre-pregnancy level on the last trimester [36]. The absolute outcome of vasodilation during pregnancy is known as systemic compensation, which shows the remarkable drop in systemic vascular resistance (SVR, 900 dynes. $\mathrm{sec}^{-1} . \mathrm{cm}^{-5}$ ) during the second trimester and the gradual increase to near pre-pregnancy levels $\left(1200\right.$ dynes. $\left.\mathrm{sec}^{-1} . \mathrm{cm}^{-5}\right)$ during the last trimester [22]. Another reason for the reduction in SVR is due to smooth muscle relaxation and overall vasodilation caused by elevated progesterone and relaxin, leading to a fall in blood pressure [37]. Diastolic blood pressure consistently decreases between 12-26 weeks, and increases again to prepregnancy levels about 2 weeks after delivery [22]. This is due to increased vascular compliance shown during the first trimester [38]. As a result of vasodilation, the reductions of SBP, and DBP are seen in this study. In fact, these blood pressures fall since early pregnancy with the lowest at the second trimester, about 5-10 mmHg below baseline [22]. No matter which pregnant support is being used, our study 
shows that reductions of SBP, DBP, and HR are particularly seen in the side lying position. These occur at the $1 \mathrm{st}$ and sustain to the end of the $3 \mathrm{rd}$ minute. This adjustment is possibly via the increase in maternal sensitivity of baroreceptors [39]. Considering the cardiac contractility during physical activity, this study found no changes in SV, end diastolic volume (EDV), and EF among different supports. This is similar to evidence from previous study in that there is no change in cardiac contractility, left and right ventricular ejection fractions during pregnancy [31].

It is believed that the size of growing fetus will further put more discomfort on the mother's pelvic organs including decreased gastrointestinal motility, prolonged transit time, and displacement of the intestines upward and outward [40]. The risks of pelvic blood vessel compression are likely aggravated by the growing fetus, which is particularly prohibited in the supine position [20]. Thus, investigation in the lateral side lying position is a standard practice for clinical maternity care provider [41]. It is speculated that exercise intolerance might possibly appear in pregnant women. However, we did not find any difficulties during exercises and daily physical activities. Possibly, the intensity of the two modes of physical stress used in this study were too low.

Questionnaires used in the present study were aimed to qualitatively estimate the feeling and perception of pregnant women while using different supports during physical activities. For ease of use, investigators simply modified a 5-point scale questionnaire $[18,19]$. For safety reasons, some select exercises were chosen for pregnant women as previously prescribed [17]. This study found satisfaction index (CW) above 3.6 out of 5. PB and PP supports. Pregnant supports in this study had been partly designed based on the Three-Point Pressure Principle [42]. With a semi-rigid portion (A band, Fig. 1) where lines of force from elastic bands point directly toward the A band. This design will prevent forward displacement of abdominal contents, as well as hyperextension of the lumbar spinal column [43]. Comfort feeling during movement is also evaluated during pregnancy according to a previous study [44]. Comfortable perception in pregnant women would be helpful for the design of maternity support that required to satisfy ergonomic needs with pain-free feeling. In our study, it seems likely that PB support is the most preferential. This finding is consistent with a recent study showing that maternity support garments are regarded as a convenient and safe device to stabilize the lumbar spine so as to relieve pain [45]. In addition, Ho and co-workers reported that maternity support garments are a convenient and easilyaccessible therapy to manage lower back pain during pregnancy and are frequently recommended and worn by pregnant women [46].

\section{Conclusion}

The present study indicates that the two common pregnant supports (pelvic band and pregnant pant) used during the last trimester assists hemodynamics adjustments of the lower limbs during postural changes. The side-lying position reduces responses of the heart while immediate cardiovascular compensations are adjusted in healthy pregnant women. Pregnant supports also exert no limitations on daily physical activity and routine pregnant exercises. The comfortable scores of pregnant supports are accepted similarly to casual wear. 


\section{Abbreviations}

CW casual wear; PB pelvic band; PP pregnant pant; DBP diastolic blood pressure; HR heart rate; BMI body mass index; BMR basal metabolic rate; SV stroke volume; $\mathrm{CO}$ cardiac output; EF ejection fraction; SVR systemic vascular resistance; SBP systolic blood pressure; SEM standard error of mean; UP upstairs; DS downstairs; STS sit-to-stand; LB lifting a light-weight box; SW 10-m slow walk; CP cat pose; DD downward dog; GP garland pose; TP tailor pose; LS lotus sit; BG bridging; GWG gestational weight gain; IM intimamedia; IAD inter-adventitial diameter; CCA common carotid artery; EDV end diastolic volume.

\section{Declarations}

\section{Acknowledgements}

The authors would like to thank Dr. Tongta Nuntakomol (MD) from Ob-Gyn Department, Thammasat University hospital and all pregnant participants. We also appreciate Thai Wacoal Limited Company for the contributions on pregnant supports.

\section{Ethics approval and consent to participate}

The current study was reviewed and qualified as an exemption by the Institutional Review Board of Mahidol University, Thailand (MU-IRB 2012/129.2607) with trial registration: TCTR20210201003 $(01 / 02 / 2021)$. All study participants provided an informed written consent form. All methods were performed in accordance with the Declaration of Helsinki.

\section{Consent of publication}

All participants consented to participate and for their data as quotations to be used. There is no individual identifying details or images contained.

\section{Availability of data and materials}

The detailed data sets used and analyzed during the study available from the corresponding author on reasonable request.

\section{Competing interests}

All authors declare no any conflicts of interest to report.

\section{Funding}

This study was partially supported from Thai Wacoal Limited Company, however, it had no role in study design, data collection, analysis and interpretation, as well as, drafting the manuscript.

\section{Authors' contributions}


KM: study design, data collection and analysis, and manuscript preparation; SB: data collection and analysis; PJ: data collection and analysis; PNC: data collection and analysis; RC: study design, data collection and analysis, and manuscript preparation.

\section{References}

1. Lumbanraja, S, Lutan, D, Usman, I. Maternal Weight Gain and Correlation with Birth Weight Infants. Procedia - Social and Behavioral Sciences. 2013;103:647-56.

2. Dehghan, F, Haerian, BS, Muniandy, S, Yusof, A, Dragoo, JL, Salleh, N. The effect of relaxin on the musculoskeletal system. Scand J Med Sci Sports. 2014;24(4):e220-9.

3. Schröder, G, Kundt, G, Otte, M, Wendig, D, Schober, H-C. Impact of pregnancy on back pain and body posture in women. J Phys Ther Sci. 2016;28(4):1199-207.

4. Gollenberg, AL, Pekow, P, Bertone-Johnson, ER, Freedson, PS, Markenson, G, Chasan-Taber, L. Sedentary behaviors and abnormal glucose tolerance among pregnant Latina women. Med Sci Sports Exerc. 2010;42(6):1079-85.

5. Leng, J, Liu, G, Zhang, C, Xin, S, Chen, F, Li, B, et al. Physical activity, sedentary behaviors and risk of gestational diabetes mellitus: a population-based cross-sectional study in Tianjin, China. Eur $J$ Endocrinol. 2016;174(6):763-73.

6. Saftlas, AF, Logsden-Sackett, N, Wang, W, Woolson, R, Bracken, MB. Work, leisure-time physical activity, and risk of preeclampsia and gestational hypertension. Am J Epidemiol. 2004;160(8):75865.

7. Guelfi, KJ, Wang, C, Dimmock, JA, Jackson, B, Newnham, JP, Yang, H. A comparison of beliefs about exercise during pregnancy between Chinese and Australian pregnant women. BMC Pregnancy and Childbirth. 2015;15(1):345.

8. Cakmak, B, Ribeiro, AP, Inanir, A. Postural balance and the risk of falling during pregnancy. $J$ Matern Fetal Neonatal Med. 2016;29(10):1623-5.

9. Yoo, W-g. Effect of wearing tight pants on the trunk flexion and pelvic tilting angles in the stand-to-sit movement and a seated posture. J Phys Ther Sci. 2016;28(1):93-5.

10. Takasu, N, Furuoka, S, Inatsugi, N, Rutkowska, D, Tokura, H. The Effects of Skin Pressure by Clothing on Whole Gut Transit Time and Amount of Feces. Journal of PHYSIOLOGICAL ANTHROPOLOGY and Applied Human Science. 2000;19(3):151-6.

11. Miyatsuji, A, Matsumoto, T, Mitarai, S, Kotabe, T, Takeshima, T, Watanuki, S. Effects of clothing pressure caused by different types of brassieres on autonomic nervous system activity evaluated by heart rate variability power spectral analysis. J Physiol Anthropol Appl Human Sci. 2002;21(1):6774.

12. Sone, Y, Kato, N, Kojima, Y, Takasu, N, Tokura, H. Effects of skin pressure by clothing on digestion and orocecal transit time of food. J Physiol Anthropol Appl Human Sci. 2000;19(3):157-63. 
13. Eungpinichpong, W, Buttagat, V, Areeudomwong, P, Pramodhyakul, N, Swangnetr, M, Kaber, D, et al. Effects of restrictive clothing on lumbar range of motion and trunk muscle activity in young adult worker manual material handling. Appl Ergon. 2013;44(6):1024-32.

14. Ryo, E, Okai, T, Kozuma, S, Kobayashi, K, Kikuchi, A, Taketani, Y. Influence of compression of the inferior vena cava in the late second trimester on uterine and umbilical artery blood flow. Int $J$ Gynaecol Obstet. 1996;55(3):213-8.

15. Fahey, JO, Shenassa, E. Understanding and Meeting the Needs of Women in the Postpartum Period: The Perinatal Maternal Health Promotion Model. Journal of Midwifery \& Women's Health. 2013;58(6):613-21.

16. Hallak, M, Bottoms, SF, Knudson, K, Zarfati, D, Abramovici, H. Determining blood pressure in pregnancy. Positional hydrostatic effects. J Reprod Med. 1997;42(6):333-6.

17. Evenson, KR, Barakat, R, Brown, WJ, Dargent-Molina, P, Haruna, M, Mikkelsen, EM, et al. Guidelines for Physical Activity during Pregnancy: Comparisons From Around the World. Am J Lifestyle Med. 2014;8(2):102-21.

18. Cunningham, GB. Development of the Physical Activity Class Satisfaction Questionnaire (PACSQ). Measurement in Physical Education and Exercise Science. 2007;11(3):161-76.

19. Cho, M-H. Preliminary reliability of the five item physical activity questionnaire. $J$ Phys Ther Sci. 2016;28(12):3393-7.

20. Kerr, MG, Scott, DB, Samuel, E. Studies of the Inferior Vena Cava in Late Pregnancy. Br Med J. 1964;1(5382):522.4-33.

21. Berg, CJ, Callaghan, WM, Henderson, Z, Syverson, C. Pregnancy-Related Mortality in the United States, 1998 to 2005. Obstet Gynecol. 2011;117(5):1230.

22. Mahendru, AA, Everett, TR, Wilkinson, IB, Lees, CC, McEniery, CM. A longitudinal study of maternal cardiovascular function from preconception to the postpartum period. $J$ Hypertens. 2014;32(4):84956.

23. Nahar, S, Mascie-Taylor, CG, Begum, HA. Impact of targeted food supplementation on pregnancy weight gain and birth weight in rural Bangladesh: an assessment of the Bangladesh Integrated Nutrition Program (BINP). Public Health Nutr. 2009;12(8):1205-12.

24. Slack, E, Rankin, J, Jones, D, Heslehurst, N. Effects of maternal anthropometrics on pregnancy outcomes in South Asian women: a systematic review. Obes Rev. 2018;19(4):485-500.

25. Wang, Y, Mao, J, Wang, W, Qiou, J, Yang, L, Chen, S. Maternal fat free mass during pregnancy is associated with birth weight. Reprod Health. 2017;14(1):47-.

26. Lukaski, HC, Siders, WA, Nielsen, EJ, Hall, CB. Total body water in pregnancy: assessment by using bioelectrical impedance. Am J Clin Nutr. 1994;59(3):578-85.

27. Lof, M, Olausson, H, Bostrom, K, Janerot-Sjöberg, B, Sohlstrom, A, Forsum, E. Changes in basal metabolic rate during pregnancy in relation to changes in body weight and composition, cardiac output, insulin-like growth factor I, and thyroid hormones and in relation to fetal growth. Am J Clin Nutr. 2005;81(3):678-85. 
28. Sha, $X Y$, Xiong, ZF, Liu, HS, Di, XD, Ma, TH. Maternal-fetal fluid balance and aquaporins: from molecule to physiology. Acta Pharmacol Sin. 2011;32(6):716-20.

29. Widen, EM, Gallagher, D. Body composition changes in pregnancy: measurement, predictors and outcomes. Eur J Clin Nutr. 2014;68(6):643-52.

30. Bader, RA, Bader, ME, Rose, DF, Braunwald, E. Hemodynamics at rest and during exercise in normal pregnancy as studies by cardiac catheterization. J Clin Invest. 1955;34(10):1524-36.

31. Ducas, RA, Elliott, JE, Melnyk, SF, Premecz, S, daSilva, M, Cleverley, K, et al. Cardiovascular magnetic resonance in pregnancy: insights from the cardiac hemodynamic imaging and remodeling in pregnancy (CHIRP) study. J Cardiovasc Magn Reson. 2014;16(1):1.

32. Robson, SC, Hunter, S, Boys, RJ, Dunlop, W. Serial study of factors influencing changes in cardiac output during human pregnancy. Am J Physiol. 1989;256(4 Pt 2):H1060-5.

33. McIntyre, JPR, Ellyett, KM, Mitchell, EA, Quill, GM, Thompson, JMD, Stewart, AW, et al. Validation of thoracic impedance cardiography by echocardiography in healthy late pregnancy. BMC Pregnancy and Childbirth. 2015;15(1):70.

34. Pickett, BR, Buell, JC. Validity of cardiac output measurement by computer-averaged impedance cardiography, and comparison with simultaneous thermodilution determinations. Am J Cardiol. 1992;69(16):1354-8.

35. Sanghavi, M, Rutherford, JD. Cardiovascular physiology of pregnancy. Circulation. 2014;130(12):1003-8.

36. Niemczyk, NA, Bertolet, M, Catov, JM, Desai, M, McClure, CK, Roberts, JM, et al. Common carotid artery intima-media thickness increases throughout the pregnancy cycle: a prospective cohort study. BMC Pregnancy Childbirth. 2018;18(1):195.

37. Fisher, C, MacLean, M, Morecroft, I, Seed, A, Johnston, F, Hillier, C, et al. Is the pregnancy hormone relaxin also a vasodilator peptide secreted by the heart? Circulation. 2002;106(3):292-5.

38. Poppas, A, Shroff, SG, Korcarz, CE, Hibbard, JU, Berger, DS, Lindheimer, MD, et al. Serial assessment of the cardiovascular system in normal pregnancy. Role of arterial compliance and pulsatile arterial load. Circulation. 1997;95(10):2407-15.

39. Leduc, L, Wasserstrum, N, Spillman, T, Cotton, DB. Baroreflex function in normal pregnancy. Am J Obstet Gynecol. 1991;165(4 Pt 1):886-90.

40. Davis, DC. The Discomforts of Pregnancy. Journal of Obstetric, Gynecologic \& Neonatal Nursing. 1996;25(1):73-81.

41. Warland, J. Back to basics: avoiding the supine position in pregnancy. The Journal of physiology. 2017;595(4):1017-8.

42. Webster, J, Murphy, D. Atlas of Orthoses and Assistive Devices. 5th Edition ed: Elsevier; 2018 25th January 2018. 480 p.

43. Hasan, SA, Hoque, M.H. Lower Limb Orthoses: A review. JCMACTA. 2008;9(1):33-6. 
44. Weisshaar, E, Witteler, R, Diepgen, TL, Luger, TA, Ständer, S. [Pruritus in pregnancy. A frequent diagnostic and therapeutic challenge]. Hautarzt. 2005;56(1):48-57.

45. Ho, SS, Yu, W, Lao, TT, Chow, DH, Chung, JW, Li, Y. Comfort evaluation of maternity support garments in a wear trial. Ergonomics. 2008;51(9):1376-93.

46. Ho, SS, Yu, WW, Lao, TT, Chow, DH, Chung, JW, Li, Y. Garment needs of pregnant women based on content analysis of in-depth interviews. J Clin Nurs. 2009;18(17):2426-35.

\section{Figures}
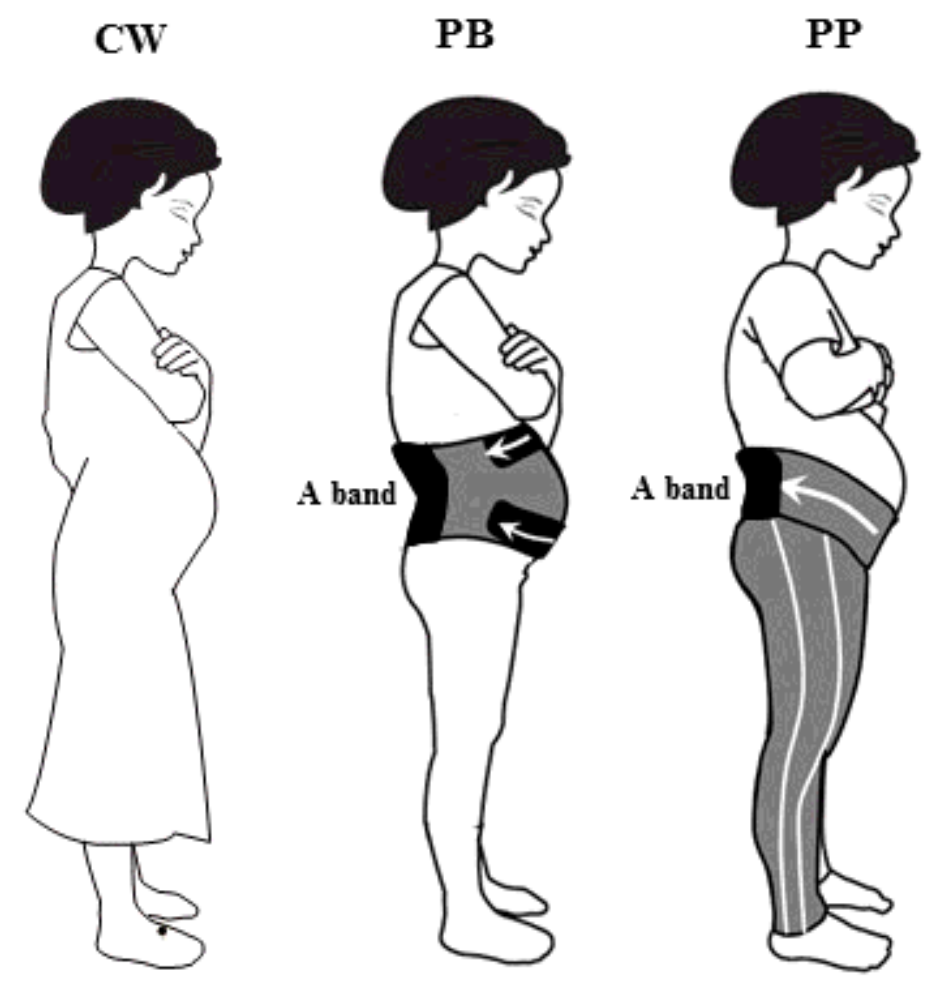

\section{Figure 1}

CW and two supports (PB and PP semi-rigid part (A band) at the lower back with vector lines of pull) used during randomized trials in last trimester pregnant women. 

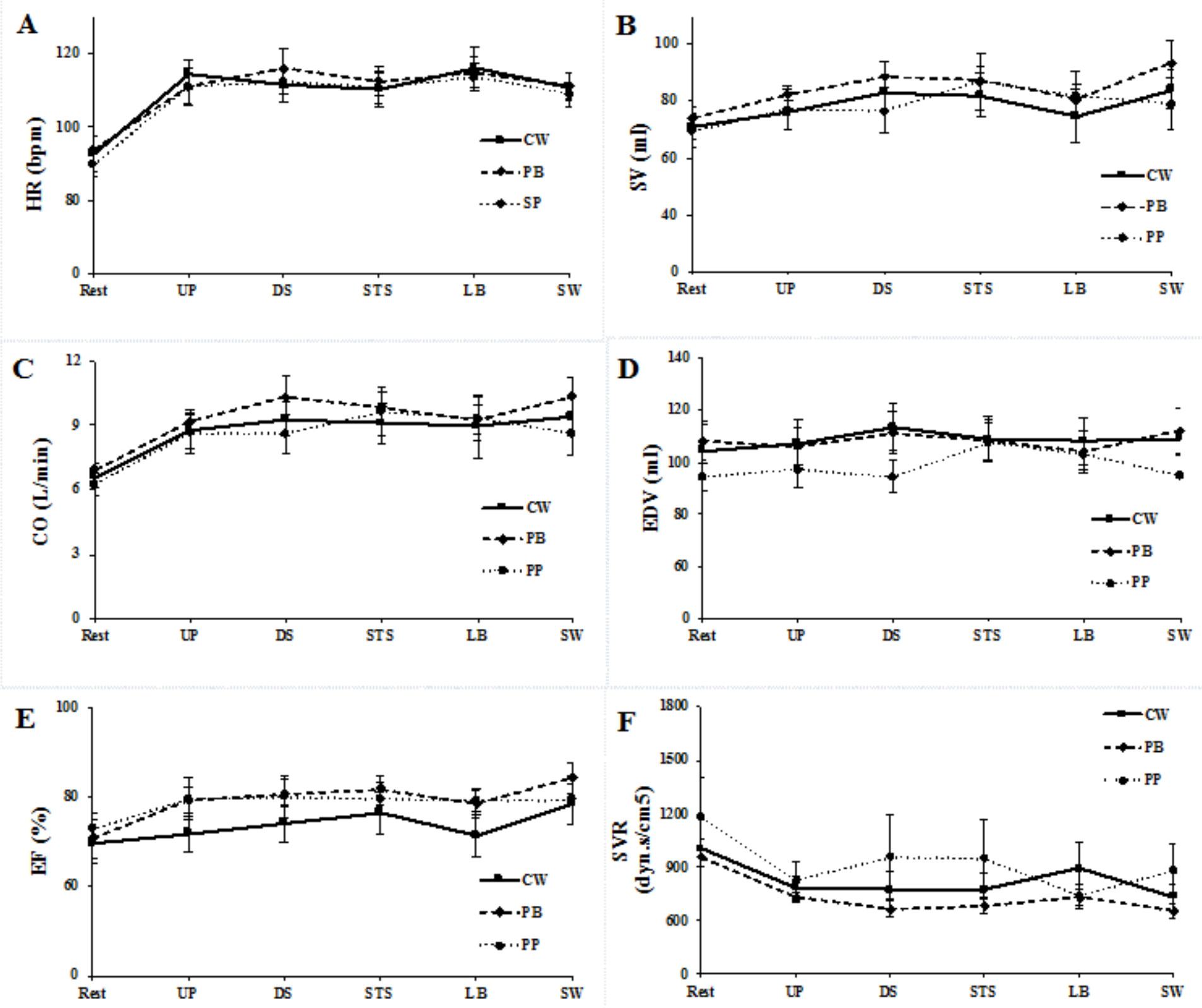

\section{Figure 2}

Hemodynamic changes from CW, PB, and PP supports during daily physical activity of upstairs (UP) and downstairs climbing (DS), sit-to-stand (STS), lifting a light-weight box (LB), and 10-m slow walk (SW). Values are means and SEM. 

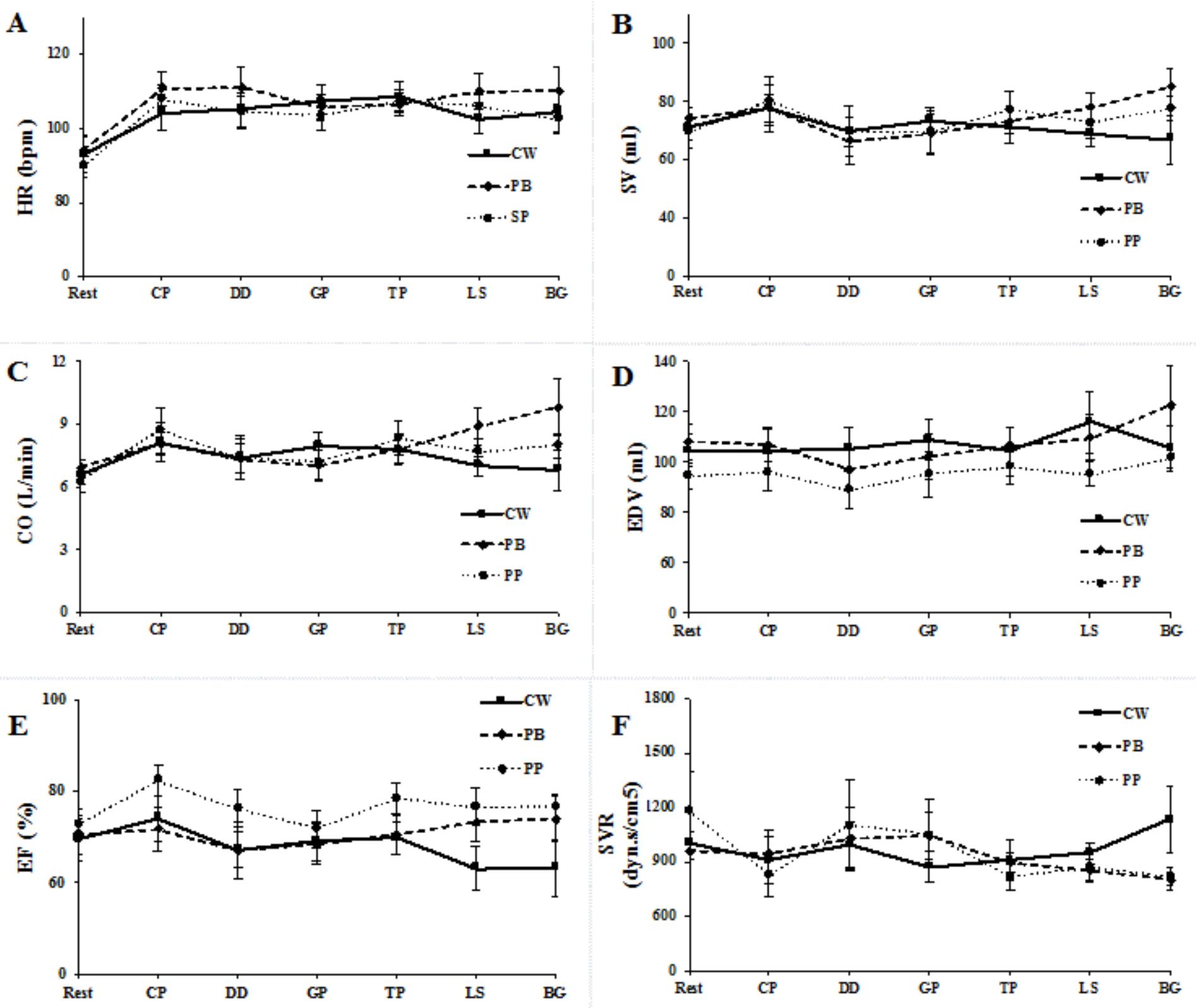

Figure 3

Hemodynamic changes from $\mathrm{CW}, \mathrm{PB}$, and PP supports during routine clinical pregnant exercises of cat pose (CP), downward dog (DD), garland pose (GP), tailor pose (TP), lotus sit (LS), and bridging (BG). Values are means and SEM. 